\title{
EDITORIAL
}

\section{The decline of industrial psychiatry}

\begin{abstract}
'This is a favourable time for ensuring that psychiatric advice in industry shall be made available on wide and sensible lines. It seems to me that much would be gained if in industrial areas the psychiatrist could make it his business ... to arrange regular visits to the larger workplaces within the area, where he could see special cases on which his opinion was desired and could discuss on the spot the problems arising out of these cases with the medical officer, personnel manager and others concerned' (Lewis, 1945).
\end{abstract}

Lewis was by no means the only leader of British psychiatry to hold such an opinion around the end of the second world war. Rees (1945) was expressing confidence that the reduction of psychiatric casualties which he had successfully pushed in the armed forces could soon be applied, with modifications, within industry; Tredgold was soon to publish his book, Human Relations in Modern Industry (1949); Ronald Hargreaves was moving from army psychiatry to become chief medical officer at Unilever (before going to WHO); Elliott Jaques was starting his pioneer application of psychiatric insights to industrial organizations at the Glacier Metal factory (Jaques, 1952); and Maxwell Jones was about to make the apparently unemployable worker the focus of his new community psychiatry experiment at Belmont (Jones, 1953), operating in close association with regional employment offices. Moreover, in view of what had been accomplished before the war, this orientation seemed reasonable, for the work of Culpin and May Smith (1936) at the Industrial Health Research Board had established clear relationships between neurosis and productivity, other workers at the same Board had produced concrete evidence of a personality factor in industrial accidents (Farmer and Chambers, 1939), Russell Fraser's (1947) widely read monograph on neurosis in industry had shown that $20-25 \%$ of all absenteeism was attributable to this disorder, and the adverse influence of some working conditions on mental health was being persuasively argued by Halliday (1948) for the coal mines. The systematic application of psychiatric principles to rehabilitation was being demonstrated at Roffey Park (Ling, 1945), and the use of the same principles to facilitate resettlement and change of employment was triumphantly succeeding in the Civil Resettlement Units, providing one of the very few instances where a programme of primary prevention has yielded unquestionable results (Curle and Trist, 1948).

In the immediate post-war era, therefore, there seemed every reason to expect that a field called industrial psychiatry or mental health services for industry would soon come into being and that by the 1970 s research in this field would have made substantial contributions. Yet the reality is very different. It is hard today to avoid the conclusion that relations between psychiatry and industry have deteriorated instead of improved during the interval and that a clear opportunity for primary prevention has been lost. In 1972 the writer, having lost contact with the field since the early 1950 s but having been invited to find new directions for industrial mental health work in one part of Canada, turned naturally to the British literature for guidance but soon sensed that matters had not moved as he had expected. In the summer of that year, therefore, he decided to find out just what had happened. The present paper is the result of his inquiry.

\section{THE DECLINE}

In the pre-war period it had been the Industrial Health Research Board which led the effort to involve psychiatry and industry with each other, and since that Board was absorbed into the Medical Research Council it was appropriate to expect the latter to perform the same function, something which initially occurred, though not for long. In the late 1940s the MRC had three units or groups which were partly directed towards mental health in industry, plus two committees. The committees were entitled Industrial Health Research and Human Relations in Industry, both of which survived until 
about 1956 but appeared to have given little guidance. The Unit for Research in Occupational Adaptation, headed by Aubrey Lewis, focused mainly (though not wholly) on the mentally subnormal entering industry, with only a little attention to the mental health of the average worker, but it did provide the expected link. The Group for Research in Industrial Psychology, which had been started in 1918, showed some initial concern for the effect of the workplace on mental health but moved steadily away from this in the direction of ergonomics, while the Applied Psychology Research Unit at Cambridge cut its links with psychiatry almost from the start. There was thus initially only a modest indication that the pre-war lead would be followed. With the mid-1950s, when psychiatry was rediscovered as an MRC field and the Unit for Research in Occupational Adaptation was changed into the Social Psychiatry Unit, matters picked up again. Rawnsley started work on the coal mines of South Wales, Carstairs at the same unit wrote a chapter for the book Modern Trends in Occupational Health (Schilling, 1960), a Group for Research into the Occupational Aspects of Ageing was founded at Liverpool, and interest in the subject was shown also at Newcastle and at Sheffield. Once again, however, these initiatives were allowed to wither. The South Wales branch of the Social Psychiatry Unit ceased in 1964; the Liverpool group, though continuing in existence until 1970, ceased to conduct research of relevance for mental health much earlier; and whereas 10 out of the 90 reports issued by the Industrial Health Research Board during its 30 years of existence dealt somewhat with mental health in the workplace, not one of the 50 special reports of the MRC since 1948 really touches the topic. By $1968-69$, the MRC had 16 units working in psychiatry, psychology, and occupational health, and many of these can be seen as having the influence of the work environment on mental health within their purview, but out of the 122 subjects which they are recorded as studying none would normally be considered to touch this subject.

Elsewhere in psychiatry similar changes have taken place. The cooperation between psychiatrists and social scientists in the immediate post-war years at the Tavistock Institute was replaced first by a sense of tension, making it difficult for individuals to maintain a balanced interest, and then by apparent indifference which Alexis Brook is now trying to overcome. Elliott Jaques gave a strong lead for a time, but his interest in the problem of rewards for responsibility (Jaques, 1956) drew him away from medicine in the direction of industrial sociology and one finds him today heading his own department of social science at Brunel University and being consulted by the national health service not as a psychiatrist or physician but as a sociologist. A. T. M. Wilson, who had once been thought of as Culpin's successor, followed a similar route a little later and is now professor of organizational behaviour at the London Graduate School of Business Studies. The Institute's social scientists, such as Emory and Rice, who initially worked together with psychiatrists, dropped this association. Hence, although this Tavistock-trained group is probably, with their various activities, making the workplace a better setting for mental health, so that psychiatrists should be interested, their approach is so indirect that few mental health workers know of it and most people in the business field do not realize that psychiatry may have contributed to the new doctrine. Tredgold has continued throughout to fight for the subject's better recognition, but seems to have found far less acceptance for this side of his work than for his undergraduate teaching. For the World Mental Health Year (1964) an international working party was formed, out of which came first the International Committee for Occupational Mental Health and then in 1970 an international conference on Stress in Industry (Kearns, 1971) at Windsor, thus keeping the subject alive. But Sir Aubrey Lewis's vision of psychiatrists visiting the larger workplaces in their area is completely unfulfilled and psychiatry as a whole seems to be showing much less interest in the possibilities for primary prevention which industry offers than it did a quarter of a century ago.

\section{ALTERNATIVE APPROACHES}

In considering why this should have happened, allowance must be made for personal factors and for the possibly greater attractiveness of some neighbouring fields. But with so large a subject-and particularly when considering the importance of industry to Britain-one seeks organizational factors as well and one of the first explanations that comes to mind is that psychiatry has lost interest 
because another discipline has taken over. No evidence of this can be found, however. The most obvious group to have assumed responsibility are the industrial medical officers and schools of occupational medicine. On that side one finds, it is true, individual physicians who have mental health well in view and who are able to pursue the subject with little or no psychiatric assistance. These are a small minority, however, with almost no backing from their colleagues and schools. The British Journal of Industrial Medicine, which averaged about two articles a year on a mental health theme in its first decade, has reduced that frequency to about $1 \cdot 2$, despite expansion in other directions. The TUC Centenary Institute of Occupational Health, which is expected to be the leader in the field of industrial medicine, has neither a psychiatrist nor a psychologist on its staff. The report of the Robens's Committee on Safety and Health at Work (1972) makes virtually no mention of mental health, although it was expected to summarize the latest opinions on its subject. The recent changes in the law affecting British factory medical services and inspection make no mention of the subject either. Here also, therefore, there seems to be a declining interest in the subject from the time when Halliday was writing about the coal miner and industrial medical officers like Smiley (1955) were still pursuing the study of neurosis in relation to the work situation.

Psychologists, personnel departments, and trade unions are other groups that could have taken over, but there is no evidence of them having done so. The National Institute of Industrial Psychology has had to focus on bread-and-butter matters such as personnel selection and aptitude testing in a struggle for survival, and although a few of its projects have had direct mental health relevance-on risk-taking, for example-these have yielded few published results. British psychology journals rarely tackle the topic; personnel and management journals tackle particular aspects-for instance, alcoholism and drug-taking among employees-but usually in a general and imprecise fashion. No trade union, to the writer's knowledge, makes use of a consultant on mental health matters, although one finds this in some other countries, and those aspects of industrial organization which should in theory be most relevant to their members' mental health receive very little attention during contract bargaining.

There is thus no reason for psychiatry to assume that the question is being taken care of by other groups, so that it can justifiably be passed over in current practice.

\section{RELEVANCE}

Since no group seems to be paying attention to industrial mental health, perhaps it does not have the relevance today that it was expected to have. Every worker in Britain has access to psychiatric services through his family doctor; conditions in the workplace have undoubtedly improved; the incidence of work-associated illness and accidents has undoubtedly declined; and machines are taking over much of what was once regarded as the dullest, dirtiest, and most dangerous work. The contact which Sir Aubrey Lewis envisaged between the psychiatrist and the workplace: has it since become unnecessary?

Close examination of the facts suggests that the opposite is true. While the clear-cut industrial diseases are declining, the percentage of sick absences due to psychological disturbance is rising. ${ }^{1}$ While the hours of work and physical fatigue are greatly reduced, the tempo of the work and the degree of mental fatigue have in many situations increased. One meets the regular complaint that, when the employer introduces machinery to take care of some routine function, he expects greater speed and precision as a result (Ferguson et al., 1965). In Switzerland it is said that the highest consumption of medication is by a group that have clean, fresh, and comfortable conditions of workthe women assembling watch parts-but who must maintain a high degree of precision. In Sweden it has been shown that the poorest mental health is experienced not by those workers who have the dirtiest or most dangerous jobs but by those who feel themselves the most alienated in their work, being given no sense of self-determination, no sense of how their work results in something useful, but instead feeling continuously supervised (Gardell, 1971). Modern industry often demands more

1Numerous figures could be cited-for instance, the fact that total days of incapacity for 'nervous debility and headache' rose from 1.9 million in 1960-1 to 4.2 million in 1967-8, according to Connelly (1970). 
mental effort of the worker than it did in the past and has put him in a position where, with his muscular aches alleviated and hunger satisfied, he has more time to think about the psychological stresses and discomforts of his situation. Mental distress, therefore, has not declined. Moreover, the machines have not eliminated all the danger and the anxiety-provoking experiences. The South Wales miner still has a high psychosomatic morbidity (Hughes, 1973). The merchant seaman is still exposed to violent weather and to the tensions that can build up in small and isolated units. And he is still prone to alcoholism (Herbst, 1969).

There is therefore no evidence that primary or secondary prevention in industry is less necessary with respect to mental health than it used to be.

\section{RESISTANCE FROM MANAGEMENT AND LABOUR}

With the need for the work apparently continuing but with no group adequately tackling it, a possibility which one needs seriously to consider is that there has been obstruction. In a report on industrial mental health services in the USA (Ferguson et al., op. cit.), this is the main reason suggested for the field's limited development there, although that development is considerably greater than in Britain. In particular, the workers are reported to have shown a great distrust of psychiatric services in industry, viewing them as means whereby management can get rid of workers they do not want or can step up production by eliminating psychological bottlenecks. Elsewhere one has heard frequently of management's resistance to studies into industrial diseases and pollution, and sometimes both management and the unions are united in resisting experimental reforms, for fear these would reduce profits and the pay-package. For these reasons the writer made it a point to enquire into possible obstruction by management or by the unions.

On the management side no instance of obstruction to mental health research or service provision was uncovered, though such obstruction was reported regarding other matters. This does not mean, of course, that they would have been ready to tolerate activities which they thought might arouse worker discontent, or that they were ready to hire any psychiatrist who offered himself, but it does mean an open mind. Hence if an area psychiatrist had wished to learn about working conditions before running a clinic jointly with some industrial medical officers, or if a well-conceived research plan were proposed, taking into consideration the interests of both management and labour, then it seems likely that facilities would be provided. The general attitude here is one of mild interest, admitted ignorance, and considerable scepticism regarding the ability of any psychiatrist or related professional to provide useful advice if he has not first learnt what working conditions in a particular industry comprise. For management, psychiatry in industry has still to prove its value and to show that it knows what it is talking about; but there is little hostility and, indeed, many management training courses do include contributions from mental health authorities.

On the trade union side the picture is a little different, with less openness at the present time but also no positive obstruction. Trade union interest in mental health has proved, if one looks internationally, to be greatest when there has been low unemployment, a broad agreement with management on the sharing of profits, cooperation with management on some other points as well, as a recognition that many workers today are seeking satisfaction from their work in addition to pay and security. Britain's labour situation in recent years has not fitted this picture and union leaders seem still too concerned with questions of security and profit-sharing to recognize the signs of another type of dissatisfaction among their rank-and-file. The type of relationship which Gardell (1971) has shown between job satisfaction and mental health cannot yet seem too relevant to them. But the TUC has a medical adviser, Dr. R. Murray, who is interested in the field, and one could expect others at their headquarters to become involved once labour-management relations improve, provided a neutral body gives a strong enough lead.

\section{OTHER COUNTRIES}

Is it psychiatry as a whole that should be giving this lead? Because of the overlapping of different disciplines in the field, this point is not clear, but one may be able to arrive at a partial answer by 
considering what research is being reported from elsewhere. If one conducts a review of the published literalure on the subject from different countries, ${ }^{2}$ then the interesting though perhaps not unexpected point comes out that the country which seems to have produced the most, in relation to its professional manpower, is that country where industrial mental health is an accepted government concern and where 'industrial psychiatrist' is a recognized appointment within the government health services.

This country is Czechoslovakia, which has been producing about half as many research papers in the field over the last 10 years as Britain has, despite having only a quarter of the population. Its industrial psychiatrists appear to be much in demand both in relation to individual patients and with respect to attempted prevention, so that the effort is not just a research one, and it has two large institutes of industrial psychology and industrial medicine. Questions of the relationship between mental health and industrial organization, such as Scandinavian researchers are particularly interested in, do not receive attention, for sociology is not a well-developed discipline in any of the communist countries. But the care of the individual worker, the types of stress produced by different tasks, the patterns of symptoms in different work groups, and rehabilitation have all received attention. One thus gets the impression that with this type of leadership research and practice go hand in hand.

Where other disciplines have taken the lead the results do not seem as good, at least from this writer's possibly biased viewpoint. In France, industrial health services are numerous and the organizations of industrial medical officers are very active, but, although there are psychiatrists employed in industrial clinics and teaching in the industrial medicine courses, there is little relationship between these and the mainstream of psychiatry. And there is little reported research. In the USA, where the neglect of this sector stands in strong contrast with the enormous volume of experimentation and research sponsored by the National Institute of Mental Health, one might say that it is management that is mainly in control, and although there are many papers being published these seem very uncoordinated, with most industries, unions, and schools of medicine ignoring the subject entirely. Sweden and Norway are pioneering in a very interesting direction-namely, that connecting mental health, job satisfactions, and organizational structure, and one could perhaps say that the lead of the sociologists there will in the long run be as productive as that of the psychiatrists and psychologists in Czechoslovakia. However, the contact between this activity and the official departments of health or schools of medicine seems weak, so that in Norway, for instance, no psychiatrist seemed to know much about it, and the nature of the sociologist's approach means that the needs of the individual are overshadowed by those of the group. One gets the impression, as in Britain, that, although individual medical men are deeply concerned about the question, their disciplines are not behind them.

One could cite regions where the lead, if any, is in still other hands-public health in Yugoslavia, for instance, and industrial psychology in Benelux. There is clearly a better chance of matters developing in large semi-governmental industries or organizations-the European Coal and Steel Authority, for instance-or where the trade unions have a strong voice in government and through this have stimulated a broad concern for the worker's welfare. However, the impression gathered by this international overview is that industrial mental health does receive better attention when it is a subject that is accepted as within the sphere of psychiatry, and particularly within the sphere of psychiatric research, than when psychiatry steps aside and waits for another discipline to take the lead.

\section{CONCLUSION}

J. R. Rees said in 1945 that 'The future of industrial psychology and of industrial psychiatry will need to be watched over very carefully if high standards are to be maintained.... The present review suggests that that warning has gone unheeded both in Britain and in the USA. There are excuses for

\footnotetext{
2The medical literature was surveyed by a ten-year MEDLA RS computer search of the Indexus Medicus, covering all languages, and eight countries were visited to obtain additional information. A balanced view of the literature, however, demands a full search of non-medical journals, for instance those on ergonomics, and this has only partly been attempted.
} 
the neglect, since the field is one in which various groups other than psychiatry could have been expected to take the lead, but there is no doubt that neglect has occurred. There is no reason to belicve that the subject has become too unimportant to bother about or that there are serious obstacles to remove before one can revive it. At the same time, there is little reason to think that the matter can be remedied simply by teaching more about industrial mental health in schools of industrial medicine and psychiatry.

It would be presumptuous for one writing from a country, Canada, where the subject is still less developed to say what should be done, but there are some obvious moves that could be made and some dangers that need to be avoided. A Medical Research Council Unit for Occupational Mental Health, for instance, seems overdue and would be completely according to tradition. However, this is a subject where too close an association with an institute of psychiatry or with a university might be a disadvantage. Also, it is much more important today than in the 1930s or 1950s to be accepted by labour, both centrally and locally. Hence, it might be better to push service-oriented research in general hospitals with large industrial clienteles, so that the researcher's affiliation would clearly be with the healing arts rather than with management or the labour exchange. The addition of a psychological approach to various health protection programmes within industry-for coronary heart disease, for instance-would be another method of starting something new without getting embroiled in management-labour disputes. But in the long run it is not merely the tolerance but the backing of both management and labour that has to be obtained, and for this they need to be shown concrete results through well-designed research and demonstration programmes.

H. B. M. MURPHY

\section{REFERENCES}

Connelly, J. R. (1970). Changing patterns of morbidity. Proceedings of the Royal Society of Medicine, 63, 1141-1144.

Culpin, M., and Smith, M. (1930). The Nervous Temperament. Industrial Health Research Board Report No. 61. HMSO: London.

Curle, A., and Trist, E. L. (1947). Transitional communities and social reconnection. Part 2. Human Relations, 1, 240288.

Farmer, E., and Chambers, E. G. (1939). Industrial Health Research Board Reports, Nos. 38, 55, and 84. HMSO: London.

Ferguson, C. A., Fersing, J. E., Allen, A. T., Baugh, N. P., Gilmore, G. A., Humphrey, J. W., McConnell, F. E., Mitchell, J. W., Sauer, J. W., and Scott, T. J. (1965). The Legacy of Neglect. Industrial Mental Health Associates: Fort Worth, Texas.

Fraser, R. (1947). The incidence of neurosis among factory workers. Industrial Health Research Board Report No. 90. HMSO : London.

Gardell, B. (1971). Produktionsteknik och arbetsglädje. En socialpsykologisk studie av industriellt arbete. PA-rådet: Stockholm.

Halliday, J. L. (1948). Psychosocial Medicine. Heinemann: London.

Herbst, P. G. (1969). Sosio-tekniske og psykodynamiske variabler $i$ planleggingen av en ny skipsorganisasjon. Tidsskrift for Samfunnsforskning, 10, 371-400.

Hughes, D. (1973). Morbidity statistics from population sur- veys. Chap. 6. In Tools of Evaluarion: an Epidemiolugical Basis for Planning Psychiatric Services. Proceedings of the Second World Psychiatric Association Symposium on Psychiatric Epidemiology, Mannheim, 1972. Oxford University Press: London. (In press.)

Jaques, E. (1952). The Changing Culture of a Factory. Tavistock: Londion.

Jaques, E. (1956). Measure of Responsibility. Tavistock: London.

Jones, M.S. (1953). The Therapeutic Community; a New Treatment Method in Psychiatry. Basic Books: New York.

Kearns, J. O. (1971). Stress in Industry. Lyons Medical Department: London.

Lewis, A. (1945). Psychiatric advice in industry. British Journal of Industrial Medicine, 2, 41-42.

Ling, T. M. (1945). Roffey Park Rehabilitation Centre. The first year's work. Industrial Welfare, 27, 88-90.

Rees, J. R. (1945). The Shaping of Psychiatry by War, p. 135. Norton: New York.

Robens, Lord (1972). Safety and Health at Work: Report of the Committee, 1970-72, Cmnd. 5034: HMSO: London.

Schilling, R. S. F. (ed). (1960). Modern Trends in Occupational Healhh. Butterworth: London.

Smiley, J. A. (1955). A clinical study of a group of accidentprone workers. British Journal of Industrial Medicine, 12, 263-278.

Tredgold, R. F. (1949). Human Relations in Modern Industry. Duckworth: London. 